\title{
Research on Development of Smart Grid in Regional Electricity Market Xiaozi Cui ${ }^{\text {, }}$, Lili Yuan ${ }^{\mathrm{b}}$, Xian Chen ${ }^{\mathrm{c}}$,Bo Chen ${ }^{\mathrm{d}}$ \\ State Grid Henan Electric Power Company Luoyang Power Supply Company, Luoyang 471000, China \\ luoyangdidiao@sina.com, 1015903240@qq.com
}

Keywords: Smart Grid, regional electricity market.

\begin{abstract}
The electric power industry as a basic industry of the national economy, responsible for a very important economic, political and social responsibility. With the development of society and economy, the whole society electricity industry increasingly high demand, and the pressure of electricity market reform is growing. As an important part of the electricity market in the supply companies, how to deal with growing economic, social pressure, the future development of the electricity market trends is a subject of concern. The internal and external environment facing the impact of regional power market for smart grid construction was analyzed to study the regional electricity market development objectives and planning.
\end{abstract}

\section{Introduction}

At present, with the development of China's rapid economic, the electric power industry as a national development strategy leading industry is the foundation of the national economy. In related industries, the power industry has a strong influence and sensitivity; it can promote and stimulate the development of a large number of industries, and plays a strong supporting role in the development of the entire national economy.

National Grid as the main business of the national electricity market, to address the problem, in 2009 issued a building "strong and smart grid" development planning. And in 2020 will be fully integrated into the "strong and smart grid", with unified planning, unified standards, unified construction principle of UHV power grid as the backbone, the coordinated development of power at all levels, build with information technology, automation, interactive Characteristics of the grid modernization. China's "smart grid" is intelligent grid, also known as "Grid 2.0" is through advanced measurement and sensor technology, advanced technology and decision support systems, advanced equipment and technology and application of advanced control methods, based on high-speed two-way communications network and integrated on the energy and power technology and automatic control technology, application of advanced control methods and highly integrated grid infrastructure and the formation of new modern grid. Now, the national grid company is building a strong and smart grid, it is to build UHV power grid as the backbone, the coordinated development of power at all levels of strong and smart grid, and the full realization of the grid automation, information technology, interactive, digital, resulting in power supply reliability, security and quality on the basis of further achieve efficient, clean and interactive goals.

\section{Ground Level Power Market Research}

With the country to promote sound and rapid economic development further implement the basic national policy, and the corresponding power industry is playing an increasingly important role in economic development, economic and social requirements for the electric power industry has become more sophisticated, and therefore, Party and government requirements and the emphasis on the power industry is growing.

Fast orderly manner "Big Five" system, coordinator of property core resources, optimize five business model, compression management level, shorten business chain, to achieve synergy and efficient operation, the establishment and operation of the power control center monitoring (control) 
center, the core of the implementation of grid operation business intensive operation, an important indicator of the company's operations to achieve real-time monitoring, speed up the completion adapt to the world-class grid, world-class enterprise "management system and operation mechanism required.

Because the construction of a strong smart grid can contribute to energy supply structural adjustment, improve the proportion of clean energy; able to build a "transmission coal both" national energy integrated transport system; to promote energy conservation; effective control of environmental pollution, promote greenhouse gas emissions; can address long-standing coal transportation problems, solve the "shortage" problem fundamentally. Therefore, the construction of a strong smart grid to promote China's development has become an important strategic fulcrum green transformation. Strong and smart grid development is the only way to solve the energy resources and demand reverse distribution, is an effective way to improve the ecological quality of the environment, is to promote low-carbon energy development an important part.

Although China's economic and social development has made great achievements, but still faces a supply of energy resources, ecological environment and greenhouse gas emission reduction capacity of the three challenges.

Supply of energy resources challenge: My mid-industrialization of high consumption of energy resources, with the deepening of heavy industrialization, rising urbanization process accelerated, the total population, the growing demand for energy resources.

Environmental Capacity Challenge: Our per capita arable land, fresh water and other vital resources are the world's average level of half to one-third. Parts of ecological destruction and environmental pollution intertwined, water, air and soil pollution, acid rain and other environmental disasters occur frequently, the ecological environment on the economic and social development constitutes a serious constraint.

Greenhouse gas reduction challenge: With the rapid economic development, our greenhouse gas emissions increased year by year, increasing global warming and seriously endanger the ecological safety. Reduce greenhouse gas emissions; climate change is the core mission of global sustainable development. Subject to the constraints of the development stage, China is faced with the dual task of economic growth and low-carbon transition.

\section{Local Electricity Market Smart Grid Construction Plans}

At the national level, the state has identified the national strategy of energy saving, energy saving is the main business, the State Grid Corporation of the energy sector as a national-level large central enterprises, the development of natural to conform to national needs in energy conservation the above play a leading and exemplary role in the development of smart grid is a very important means of low-carbon energy is realized. From the national grid itself, the State Grid Corporation has identified three five and UHV development strategy, which gives low-carbon power grid and production safety have presented a huge challenge, where the development of the smart grid is to overcome these challenges in a very important way.

\subsection{Generation Sector}

Application of new energy generation system simulation technology, power prediction technology and operational control technology, renewable energy and orderly grid to meet the power needs of a variety of access. Reinforcing net factory coordination, realization generator excitation system, a frequency modulation, real-time monitoring of operating conditions, analysis and management, conventional quick adjustment and depth peaking units and other flexible operational technology has been widely used. Promote energy-saving power generation scheduling, optimizing the power structure, to achieve the harmonious development of the power grid and promote the rational use of energy.

\subsection{Transmission Link}

2016 line monitoring equipment set, completion of a comprehensive coverage of Power transmission line condition monitoring and disaster warning center. Actively promote the "two-three 
new" line construction, improve the transmission capacity of the line.

\subsection{Substation Link}

Accelerate the intelligent substation construction and renovation. The construction of advanced substation, the main equipment, intelligent, comprehensive hub and center substation built or transformed into intelligent substation; Intelligent equipment for effective monitoring, flexible control, device information, and operation and maintenance strategy and power dispatch fully interactive; safety substation equipment stable operation.

\subsection{Distribution Link}

Continuous improvement and continued to strengthen on the basis of a strong distribution network construction, according to the smart grid development objectives and overall requirements, in line with economic, practical, advanced principles, advancing the distribution network automation, information system construction, to carry out the regulation of distribution network integration intelligent technology support system with network equipment condition monitoring and diagnostics, intelligent fault diagnosis technology related research and pilot projects to promote the application and carry out unified strong and smart distribution network construction work. Ensure strong distribution network, flexible, intelligent, efficient operation. 2016 city network distribution reliability rate of $99.99 \%$, rural power distribution reliability rate of more than $90 \%$; the voltage passing rate of more than 99 percent urban and rural power more than 98\%; urban network distribution line loss rate drop to $5 \%$ or less, to $10 \%$ and less rural network.

\subsection{Electricity Link}

According to State Grid Corporation of smart grid companies and electricity sectors overall objectives and requirements, through marketing management innovation and technological innovation, promote service innovation and institutional innovation. Strengthening research the application of new technologies; intelligent appliances, intelligent two-way interactive system of intelligent power cell; electric vehicle charging station discharges key technology research and application means and the charging and discharging control system. The full realization of municipal electricity supply zone information automatically precludes the collection, coverage of 100\%. 20 KVA and above county-level power supply area of electricity customers to automatically collect information rate is $100 \%$.

To carry out the construction of the Intelligent Community, preclude the use of optical fiber composite low-voltage cables (Ethernet passive optical network technology and communication technology to achieve power FTTH, triple play services, as well as information collection and low voltage distribution automation, electric vehicle charging pile, PV systems provide access; to achieve a variety of information gathering cell, analysis, processing, control, and utilization of information related subsystems, and residential property management subsystem and '95598 interactive business intelligence community to achieve integration; through an interactive display platform to realize the intelligent cell system integrated display.

\subsection{Scheduling Link}

Smart grid scheduling technology support system construction, application-based services, "UHV AC and DC, multi-level" big economic security and stability operations, implementation of forward-looking panoramic warning, co-ordination of risk assessment, analysis and decision optimization, multidimensional coordination panoramic integrated smart grid scheduling decisions system control, standardized process management, efficient information and communications features to build advanced and applicable technologies, standards, standardized, features well-equipped, safe and reliable, smart grid scheduling system energy saving economy. Years ago, the provincial dispatch completion of a comprehensive smart grid scheduling technology support system; ground-level scheduling technology support system fully with the support of "control one" function, which is to adjust in accordance with the requirements of the completion of the standardization of smart grid scheduling technology support system of land transfer on the existing system functional expansion, full support "control one" work. 


\section{Summary}

This paper presents a plan of recent construction of smart grid in area. Including the basis of existing power grid development results, information technology, automation, and interactive features of the grid as the goal, according to "overall planning, unified standards, the pilot first, overall progress" approach, adhere to the "unified planning, unified standards , unified construction "work thinking, strengthen the unified leadership combination of distance, coordination, system planning smart grid construction. Adhere to the grid "smart" and "strong" high degree of integration; achieve the coordinated development of all sectors of intelligent network.

\section{References}

[1] Li W, Yang Q, Zhang H, et al. Incentive mechanism research on accommodation of wind power in regional electricity market based on cooperative game[J]. Renewable Energy Resources, 2014.

[2] Regional I. Practical Research on Settlement Mode of Transacted Electricity Quantity in Regional Electricity Market[J]. Power System Technology, 2008, 32(3):56-61.

[3] Zhang S. Practical Research on Compensation Mechanism of Ancillary Service in Regional Electricity Market[J]. Water Resources \& Power, 2008.

[4] Park M G, Cho S B, Kim K H, et al. Development of Operation Strategy in Jeju Smart Grid Test-Bed Electricity Market.[J]. Communications in Computer \& Information Science, 2011.

[5] Zhang L, Huang R. Effects of Smart Grid on Electricity Market Development and Prospects[J]. Automation of Electric Power Systems, 2010, 34(8):5-10.

[6] Zhu H L. Research on Congestion Cost Allocation in Regional Electricity Market[J]. Guangdong Electric Power, 2008. 